\title{
A Diverse Inspirational Language-Teaching Approach
}

\author{
Omid Talebi Rezaabadi \\ Deakin University, Australia \\ E-mail: omidreza1365@yahoo.com
}

Received: 01-08-2016

Published: 10-12-2016
Accepted: 05-10-2016

doi:10.7575/aiac.ijalel.v.5n.7p.19
Advance Access Published: November 2016

URL: http://dx.doi.org/10.7575/aiac.ijalel.v.5n.7p.19

\begin{abstract}
In this article, a pedagogical strategy named 'A Diverse Inspirational Language-Teaching Approach' is proposed and empirically analysed. Existing classroom procedures for learning English as a foreign language (EFL) are described, and the need to include fun, variety and inspirational adages in language teaching is emphasised. The pedagogical effectiveness of a virtual-learning environment is evaluated, along with that of a 'Universal Language Village' created by the teacher to enable the students to practise English in a second language like context. A questionnaire was developed to obtain information on the students' perceptions of the effectiveness of the above teaching approach. The findings indicated that the students' general impression of the approach was positive. The results also suggest that overall, the proposed strategy is likely to enable beginner EFL students to become competent language users, as measured by their scores in the International English Language Testing System proficiency test.
\end{abstract}

Keywords: speaking language, teaching method, EFL, language-teaching approach, exploratory approach

\section{Introduction}

The goal of every new teaching method is to provide a more effective and theoretically comprehensive basis for teaching than previous methods. For example, in the late $19^{\text {th }}$ century, the 'direct' method of teaching was developed to shift the emphasis from learning grammar to speaking language on a daily basis in practical contexts. This method involves phonetics teaching and question and answer oral tasks. Speaking skills and listening skills are emphasised. Grammar is only taught 'inductively'. No translation is allowed, and self-correction is emphasised (Larsen-Freeman, 1986). The direct method, albeit with modifications, is still widely used.

In the $20^{\text {th }}$ century, the method of community language learning (CLL) was developed, and continues to be widely used in modified form. Using this method, students collaboratively determine their language-learning content. CLL is related to the counselling approach to learning, wherein the teacher acts as a counsellor and learners as clients and partners. The main purpose of this method is to help foreign-language (FL) learners to improve their communicative skills. While helping students to translate utterances from their mother tongue into the target language, the teacher conveys relevant information on pronunciation, grammar and vocabulary. The teacher also encourages learners to express their feelings. Speaking and listening skills are emphasised (Richards \& Rodgers, 2014).

Another language-teaching method commonly used today is total physical response (TPR), developed by James Asher. The teacher gives instructions to his/her students in the target language and asks them to respond with physical movements, as when they learned their first language. Asher believes that teaching should decrease stress and that listening should precede speaking, just as during first-language learning. Using TPR, grammar is taught inductively (Richards \& Rodgers, 2014).

Since Howatt's (1984) research, only a few original studies of English as a FL (EFL) teaching have been published (Howatt \& Smith, 2014). As a result, novel methodologies should be introduced to mainstream EFL teaching to add variety; these methodologies should be concise, pedagogically effective and based primarily on innovative research rather than received wisdom. In this paper, therefore, we analyse an experimental and mostly original approach to EFL teaching, developed by Omid Talebi Rezaabadi and named 'A Diverse Inspirational Language-Teaching Approach'. We argue that this approach enables EFL learners to achieve language proficiency more rapidly than approaches to EFL that neglect the role of inspiration and pedagogical diversity in language learning. Using the proposed approach, a teacher can continuously motivate his/her students and elicit their enjoyment and enthusiasm through music and sports, enabling learners to overcome negative emotional challenges that impede their learning. A range of techniques is used to teach language skills, creating a more comprehensive foundation for learning. The use of a 'story' framework is also shown to make grammatically correct sentences more meaningful and thus easier to learn.

Little is currently understood regarding the efficacy of virtual-learning environment, with that of a 'Universal Language Village' invented by the teacher of this study to enable the students to use English in a second language like context. The principal aim of this study is to help fill the gap in the literature on language-teaching innovation by discussing the step by step implementation of a novel exploratory approach to EFL teaching. Next, the students' perceptions of and 
responses to this approach are described. Finally, the students' language proficiency levels after experiencing the proposed approach to EFL learning are measured and reported.

\section{Research questions}

The study is guided by the following two research questions.

1. What are the students' perceptions of learning English using the proposed language-teaching approach?

2. Can the proposed language-teaching approach enable beginner FL learners to become competent language users?

\section{Methodology}

\subsection{Participants and Context}

The students who participated in the study were 30 Iranian learners undertaking an intensive EFL programme at an English-language institute in Iran, divided into three classes of 10 students. The instructor was a dedicated and professional teacher who had taught English at university level for more than 13 years.

Although the majority of the learners involved in the study (66 per cent) were studying English in preparation for applying to universities across England, the US and Australia, a substantial proportion (34 per cent) were studying English to meet professional requirements in their home country.

The participants were drawn from three beginner-level classes. The results of interviews and placement tests suggested that their English vocabulary comprised fewer than 77 words. They attended the classes for 3 days a week for 2 hours per day over a 26-week instructional period.

The students' ages ranged from approximately 16 to 28 , with an average of 21 . Twenty-one of the participants were adults, and nine were adolescents. The majority of the participants were female, with a female to male ratio of 19 to 11 .

\subsection{Instruments}

Information on the subjects' proficiency was obtained using two measures: interviews and the International English Language Testing System (IELTS) proficiency test, administered as a pre-test and a post-test, respectively. The interview test, which was conducted to confirm that the students registered on the course were beginner-level learners, consisted of two parts: a vocabulary section and an interactive section. The first section lasted for 5 minutes, during which an interviewer asked simple vocabulary questions using words such as 'cat', 'dog', 'door', 'basket' and 'family', and an evaluator assessed the student's vocabulary knowledge from his/her answers. During the second section, each student was asked some commonplace questions in English, such as 'How old are you?', 'What colour is it?', 'What does your father do?' and 'How many people are there in your family?', for another 5 minutes.

The IELTS proficiency test, which was performed to test the learners' proficiency levels after their 6-month EFL course, comprised four subtests: listening, reading, writing and speaking.

\subsubsection{Questionnaire}

A novel questionnaire was developed to elicit the students' opinions of the proposed approach to EFL teaching, in two dimensions: (1) their general impressions, (2) their perceptions of the approach as fun and motivating. The questionnaire comprised 10 statements with which students indicated their agreement/disagreement on a 5-point Likert scale (see table 1 and table 2), ranging from 1 to 5 . A higher value for a given item corresponded to a more positive impression of that item.

\subsection{Procedures}

With the participants' permission, cameras were installed in the students' three classrooms to enable detailed observation of the teacher's instructional approach and the students' learning. The three classes were taught by the same teacher. All 30 students agreed to take part in a questionnaire survey at the end of the course to express their opinions of the instructional procedures used. The most common answers were recorded. After their 6-month EFL course, the students took the IELTS Academic test to assess their level of proficiency and determine whether they had moved beyond beginner level.

\subsubsection{Experience}

On entering the class, the teacher loudly and enthusiastically greeted the students in the target language, while smiling broadly. The students, whose English vocabulary was limited, did not understand everything that the teacher said; however, they understood from the teacher's facial expression and tone of voice that he was greeting them. Next, the teacher shifted to the students' mother tongue to describe the content of the 6-month course. He also explained how important English is, and that their lives would be better after learning English. 'To demonstrate the effectiveness of this approach,' he said, 'I invite you to observe students who have finished this course and are now at an advanced level.'

After explaining the advantages of phonetics-based learning, the teacher distinguished between consonants and vowels in English. He taught consonants first, which seemed easier for the students, followed by vowels. Vowels with a similar pronunciation, such as 'i:' and ' $\mathrm{i}$ ', were taught together to aid comparison. The teacher told the students that pronouncing different vowel sounds in the same way could change the meaning of a word and thus cause misunderstanding. 'For example,' said the teacher, 'if you were to pronounce the word "ship" like "sheep" in the US, they would sell you a sheep to ride instead of a ship to travel in'. The teacher smiled, and the students began to laugh.

'Do you want people to like you, and do you want to enjoy speaking in English? Yes or no?'

'Yes, of course!' said the students. 
'Then repeat the words as loudly and as accurately as possible to adapt your vocal cords and mouth to English intonation and pronunciation. It's like singing: if you have a good voice, you will enjoy singing to yourself.'

Later, the teacher played words from a tape spoken by an authentic target-language speaker, and asked his students to repeat the words after him, complimenting them on their performance.

In the next class, the teacher directed his students' attention to a booklet on speaking in English, which provided general grammatical information on tense and word order in English. The teacher first reminded the students of the construction of imperative sentences in their mother tongue ('infinitive without "to" + object + adverb of manner + adverb of place + adverb of time'), and gave them many examples to familiarise them with the process of translating imperative sentences from their mother tongue into the target language. Next, the teacher wrote a scrambled sentence for the students in their mother tongue and asked them to translate it into English. If the students experienced problems, he drew their attention to the word-order examples and asked them to correct their own work. In the same session, he taught other imperative structures: the negative imperative, the 'let's' imperative and the 'let's not' imperative. The teacher asked the students to translate 36 words from their 'Practical Words' booklet from their native language into English, in accordance with the words' exact phonetic structure, before the next class. He also gave each student a compact disc (CD) with a recording of all of the words in the booklet, enabling the students to check their pronunciation.

'Try to learn the words with enthusiasm and have fun with them; try to relate the English words to words in your native language to help you memorise them. For example, the word "parrot" in English means "your feathers" in your mother tongue, and because a parrot has beautiful feathers, you can relate these words to each other.'

'But we can't relate all of the English words to words in our native language,' one student commented.

'It doesn't matter even if you can't, because playing with the words and making an effort to find connections between them will ensure that they stick in your mind.'

In the next class, after giving the students a quiz on the words they had learned, the teacher attempted to identify and resolve the students' problems with the words. Next, he played an authentic English film to show the students how romantic and melodious their accents could be if they stressed the syllables of the words in accordance with rules of phonetics.

After the second 2 weeks, the teacher explained the importance of careful listening to English learning, occasionally shifting to the students' mother tongue to ensure that they all understood. He asked the students how they had acquired their own mother tongue or southern accent.

'What does "acquire" mean?' asked one student.

The teacher referred her to an 'English in English' dictionary in the middle of the table and asked a volunteer to look up the word and read it out to the class. The students demonstrated their understanding of the teaching process: 'First, we listen.'

'Sure: standard listening leads to standard speaking,' the teacher agreed.

After making the importance of listening clear to the students, the teacher wrote down some key components of spoken English that they would encounter while listening. For instance, he taught them some informal expressions in English, such as 'wanna', 'gonna' and 'gotta'. Next, he played a CD with a recording of the authentic target language and asked the students what they could hear. After the students had answered, the teacher played the sentences on the CD again and asked the students to repeat them after him to ensure that everybody had noticed the use of the previously taught listening points. The recording comprised 20 sections, each of which lasted for 4 or 5 minutes. The teacher worked on one section per class. Before beginning the course, the students had received copies of the $\mathrm{CD}$ without headings for its various sections, enabling them to practise their vocabulary. Most of the section headings were inspirational, such as 'the importance of ambition', 'the importance of self-confidence', 'no pain, no gain' and 'the daily use of English in our lives'.

In the next class, the teacher played the $\mathrm{CD}$ again, and the students took turns to repeat what they heard. When the students stumbled over the words or stopped speaking, the teacher told them, 'I want you to say whatever you hear, even the rhythm or the sounds that you hear, because even your own incomplete utterances can improve your listening and help you to separate the words in your mind.' After working on the sentences, the teacher provided the title for this section of the recording and told the students that in the next class he would ask the students to say the sentences studied at random. 'Not only will you have to say the exact sentences; you should also try to pronounce them as accurately as possible.'

After a month, once the students had mastered the basic grammatical structures of spoken English and commonly used English words, each 2-hour class was divided into three parts: listening, speaking and story-telling. At the beginning of the speaking section, the students were asked to recall the words they had previously learned.

'From now on, you should be prepared to speak English in free discussion in the second part of your class,' said the teacher.

'We can't speak English,' said one student.

'I know that this is your first experience, and it's really hard for you; I just want you to do your best and have fun, and whatever you can't say, ask in English, "What is the correct word in English?"

The teacher's next question was, 'What do you think about the advantages and disadvantages of money?'

One student commented, 'It would allow me to buy a house or a car.'

'Thank you, very good, that's all I want: for you to do your best,' said the teacher. The students took turns speaking, and were enthusiastically complimented and inspired by the teacher, regardless of the quality of their 
speaking. After speaking, the teacher told them to open their 'story' booklet, which provided a range of wellknown popular stories written in their mother tongue. In front of each sentence, a reference was given to a page number in the booklet with information on the relevant points of grammar and vocabulary. The teacher began with a story named 'Mr Brown', which was constructed from simple sentences and offered a good place to start for English story-telling. If the students made grammatical mistakes when translating the sentences into the target language, the teacher drew their attention to the part of their 'speaking' booklet focused on grammar. After teaching them the relevant grammar with many examples, he asked them to correct their own work.

During the listening section of the next class, when the students' intonation and pronunciation differed from that of the $\mathrm{CD}$, the teacher played the recording back and encouraged them to speak in a more native-like way, as this would increase their enjoyment of the language. He played another section of the $\mathrm{CD}$ and asked one student at a time to repeat the sentence heard. When one student understood only the words 'what' and 'doing' in the sentence 'what are you doing?', the teacher encouraged him to use his grammatical knowledge to guess the remainder of the sentence. After a pause, the student gave the full sentence, and the teacher responded with a compliment: 'Excellent.' Another student failed to understand the words 'When did' in the following dialogue: 'A: "When did you arrive?", B: "Two months ago"'. The teacher instructed the student to focus on the whole context rather than on single sentences or single words when listening. 'If the answer is "two months ago", what might the question be?' The student answered correctly: 'When did you arrive?'.

In the speaking part of the class, the teacher spoke only English, and told the students to imagine that they were in an English-speaking country and had no choice but to speak English. Therefore, they had to ask 'What is the correct word in English?' when they wished to translate a word from their native tongue into English. The teacher also told the students to join an English-language group called 'English Booster' in WhatsApp Messenger, a mobile-messaging application. Almost all of the teacher's advanced and intermediate English learners were part of the group, which enabled them not only to exchange information but to send English music, English poems and helpful proverbs in English to others to boost their English while having fun.

In the next class, one of the students misheard the word 'unhappy' as 'happy'. The teacher repeatedly played the CD until the student said, 'Oh sorry, the word was "unhappy", not "happy".' The teacher demonstrated the correct pronunciation of the word by putting the correct stress on the letter ' $h$ ' in the word 'unhappy', and explained the importance of stresses in English. The teacher provided examples of previous students who had had similar problems, such as those who had misheard the words 'upset' and 'upstage' as 'set' and 'stage', respectively.

During the speaking part of the class, the teacher told the students that from that point onward they would be required to express their feelings about their learning experience in English. He reassured his students that if there are eight people in a class, they are eight friends, and no-one should be ashamed of expressing their thoughts in front of their friends. 'You should behave like babies,' the teacher advised. 'Don't be afraid of making mistakes when learning the language until you become accustomed to speaking in English.'

'I can't help my stress, teacher,' one student commented.

'You know, my dear,' the teacher replied, 'we experience two kinds of stress: first, positive stress, which I call "strong will". This increases the flow of blood to our muscles and carries glucose to our brain, making us better learners. The other is negative stress, which I call the "bogeyman". Negative stress is caused by something that doesn't exist, which we have made up in our minds, and which impedes our learning.'

'But this is real, teacher,' said the student. 'I am afraid of seeming a fool to you and my friends.'

'As your teacher, I know that mistakes are part of your learning, and it is my job and duty to correct you; if you did not make mistakes, you would be teachers, not students, and I would not have a job.' The teacher laughed along with the students. 'Now, I want you to think about the reasons for your anxiety; then you will understand that they are nothing but your own imagination. If you are scared of the bogeyman, try being in the dark; if you are scared of heights, stand in a high place; and if you are scared of speaking the target language, simply try speaking it. I can assure you that these kinds of illogical stress will disappear after a while.'

'Thanks, teacher, that was really reassuring,' the student replied, smiling. Next, the teacher quietly played a piece of light, beautiful music to the class and told the students to have fun talking about the importance of love to our lives.

For the remainder of the course, the teacher implemented a different approach to speaking in each of the three weekly classes, and played a different kind of light music in each session. The approaches to speaking included making a story from new words, retelling a memory described by the teacher, talking about an episode of a television series, role playing and free discussion. The students also spoke English when playing sports such as dodgeball, volleyball and football on their field trips; they were required to speak English throughout the games. For example, when they dodged the ball during dodgeball they had to say 'dodge', and when they were hit by the ball they had to say, 'Oops, I was hit by the ball!'

In some classes, the teacher invited the students to learn in a place named the 'Universal Language Village' created by the teacher to enable his students to practise the language in an environment similar to a second-language context. First, the students were introduced to a model village, comprising various rooms in which small toys had been positioned to indicate their functions: a restaurant, an airport, a hospital and an ice-cream parlour. The rooms looked like children's playrooms. The teacher asked the students to take on roles suited to the rooms. For example, they played the roles of a doctor and a patient in the hospital-like room, observed by their teacher, who noted down their speaking mistakes for later correction. Eventually, after the students had understood what to do, they were invited to live together for a week 
in the real version of the Universal Language Village, a camp-like environment, during which they were not permitted to use their mother tongue at all. During this week, the teacher acted not as a teacher but as a family member: simply another resident of the Universal Language Village. The teacher helped to make the discussion fun and interesting. Everybody spoke English, even when preparing and eating meals together. One week later, the teacher explained their speaking mistakes in class.

After 3 months, once the students' vocabulary had reached an appropriate level, almost 1400 words, the teacher introduced as a listening activity a song that contained more words and idiomatic expressions in English. The teacher taught them how to sing along with a song named 'Hello', one of the most successful songs released by the well-known popular singer Adele, and one of the students' own favourite pieces of music. While the students were singing, the teacher paused the song and said, 'Now I want to pronounce the words of the song with and without the right stress patterns.' After saying the word 'hello' twice, once with and once without the appropriate stress on the letter 'l', he showed the students how much more romantic their singing could be if they obeyed the phonetic rules of English.

For the last 2 months of the course, the teacher introduced a different type of listening activity to each of the three weekly classes. The topics of the first, second and third weekly sessions were 'an original English film', 'the news' and 'songs', respectively. In the meantime, to improve the learners' reading skills, the teacher moved from easy reading texts such as the fairy-tales of Cinderella and Snow White to more difficult texts such as 'The Crisis of Poverty', which he asked the students to read at home. Any problems with their reading were raised in class.

\section{Results}

Process-oriented evaluation was conducted to assess the language-teaching practices involved in the proposed exploratory language-teaching approach, and the learning outcomes of this approach. 'Process-oriented research is primarily descriptive in nature and is intended to generate hypotheses concerning relationships between specific instructional practices and learning outcomes' (Spada, 1987, p. 137).

To answer the first research question, the students' responses to the open-ended questionnaire were collected at the end of the course. Their responses provided information on their general impression of the language instruction (see Table 1) and the extent to which they considered the approach fun and motivating (see Table 2). The students' overall impression of the proposed learning approach was positive (mean $=3.708)$, and $68 \%$ of them agreed that the approach had positive effects.

Most of the students (mean $=4.57$ ) agreed that the learning contexts introduced - such as the Universal Language Village and the sports fields - were effective. However, when asked whether they felt comfortable with the proposed approach, the majority of the students expressed neutral responses (mean $=2.98)$. The teacher's inspirational adages and rhetoric were generally perceived as beneficial; most of the students (mean $=3.64)$ confirmed that this type of speech aided their learning $($ mean $=3.64)$. Similarly, almost all of the students $($ mean $=3.17$ ) agreed that the proposed approach was creative and efficient (see Table 1).

Table 1. Students' perceptions of language instruction

$\begin{array}{lll} & \text { Mean } & \text { Standard Deviation (SD) } \\ \begin{array}{l}\text { 1. 'A Diverse Inspirational Language-Teaching } \\ \text { Approach' is an effective learning strategy }\end{array} & 4.42 & 0.48 \\ \begin{array}{l}\text { 2. I feel comfortable about taking part in this } \\ \text { approach to learning }\end{array} & 2.98 & 0.65 \\ \begin{array}{l}\text { 3. The teacher's inspirational adages and } \\ \text { psychological strategies are effective. }\end{array} & 3.64 & 0.73 \\ \begin{array}{l}\text { 4. The interactive contexts created during this } \\ \text { approach, such as the Universal Language } \\ \text { Village, the, virtual-learning environment and } \\ \text { the sports field, are effective. }\end{array} & 0.64 \\ \begin{array}{l}\text { 5. The teacher's inspirational adages and } \\ \text { psychological strategies are effective. }\end{array} & 4.57 & 0.73 \\ \text { Overall } & & \mathbf{3} \\ \end{array}$

The students' perceptions of the extent to which the proposed approach was fun and motivating were also disclosed in the questionnaire. The students responded positively to all five statements, with an overall mean of 3.72. The students recorded a high mean total score of 4.33 for 'feeling inspired to learn' by this approach to language teaching, and a fairly high mean of 3.25 for 'feeling inspired to learn by the teacher and his language teaching'. The participants recorded high scores for having fun in the interactive contexts of the Universal Language Village, the virtual-learning environment and the sports fields (mean $=3.57$ ). Interestingly, these scores were even higher than their overall scores for having fun while learning using the proposed approach (mean = 3.92). A mean score of 3.44 indicated that they felt motivated enough to learn using this approach (see Table 2). 
1. I feel motivated to learn English by 'A Diverse Inspirational Language Teaching Approach'

$\begin{array}{ll}\text { Mean } & \text { SD } \\ 3.44 & 0.52 \\ 3.92 & 0.87 \\ 4.33 & 0.71 \\ 3.57 & 0.95 \\ 3.25 & \\ \mathbf{3 . 7 2} & \mathbf{0 . 7 3}\end{array}$

Although IELTS scores are usually given in whole numbers from 1 to 9 , the scores obtained in this study were calculated and recorded to several decimal places to ensure that the students' scores could be evaluated precisely. The means of their IELTS scores at the end of the course were as follows: speaking: 6.3 ; listening: 4.48; reading: 5.43; and writing: 5.38 (Table 3). To aid the interpretation of the scores, Table 4 describes the nine bands into which IELTS Academic scores are categorised. To answer the second research question, the results in the table suggest overall that the participants, initially at beginner level, had become competent users of the English language by the end of the course, as they were able to understand and use the complex language to a fairly high level.

Table 3. Students' IELTS scores at end of course

\begin{tabular}{lcccc}
\hline Subtests & Speaking & Listening & Reading & Writing \\
\hline Mean & 6.3 & 4.66 & 5.43 & 5.86 \\
Overall Band Score & & & 6 & \\
SD & 0.38 & 0.49 & 0.63 & 0.41 \\
\hline
\end{tabular}

Table 4. IELTS description of band scores

Band

$9 / 8 / 7 / 6 / 5 / 4 / 3 / 2 / 1$

\section{Description Expert user/Very good user/Good user/Competent user/Modest user/} Limited user/Extremely limited user/Intermittent user/Non-user

\section{Discussion}

Although it is difficult to determine the efficacy of an FL teaching approach in just one study, and without a control group, the results of this research suggest that the proposed approach, A Diverse Inspirational Language-Teaching Approach, was effective. One significant finding of the study was that the students gained a generally positive impression of learning using this approach (see Table 1 and Table 2). The other significant finding was that beginnerlevel students whose English vocabulary was smaller than 77 words had become competent EFL users by the end of their 6-month course. Certainly, the proposed approach exhibits key similarities to and differences from other methods of FL teaching, of which the most noticeable are as follows.

Some features of the proposed approach are similar to those of the direct method; others differ. One of the major similarities is that both methods emphasise phonetics and accurate pronunciation from the very beginning. However, whereas the teacher observed in this study used a combination of the mother tongue and the target language to inspire his students and teach them the main grammatical points, especially at an early stage of EFL learning, the mother tongue is never used by practitioners of the direct method.

The current approach is also similar to CLL in many respects. In both, speaking and listening skills play major roles, and translation from the students' mother tongue into the target language is emphasised. However, in the CLL classroom, students begin by speaking in their mother tongue with no planned topic; next, the teacher shows them how to translate their mother tongue into the target language by teaching them context-appropriate grammar and vocabulary. In contrast, using the approach proposed in this study, the students receive approximately a month of instruction, during which the teacher teaches them the basic grammatical components of sentences and tests their understanding of about 36 basic words in each session, before beginning to write and speak in the target language using a story booklet. 
Another approach somewhat similar to the proposed language-teaching approach is TPR. Both approaches emphasise the importance of combining speech with physical movement. However, TPR practitioners give their students instructions in the target language and ask them to respond to these instructions physically, just as when learning their mother tongue. Using the proposed approach, students play games on sports fields and speak in the target language while playing sports. The most salient difference between the two approaches is the variety of speaking techniques used in the proposed approach, which are not limited to physical movement. For example, students may be asked to invent a story using new words, retell a memory described by the teacher, talk about films and participate in environments very similar to second-language contexts, such as the Universal Language Village and virtual-learning environments. This enables the students to have fun while speaking in the target language.

According to the creator of the proposed approach, based on his many years of experience of EFL teaching, the following principles underlie the various steps taken during this approach.

\section{Procedure}

On entering the class, the teacher greeted the students loudly and enthusiastically in the target language, while smiling broadly.

The teacher shifted to the students' mother tongue to describe the content of the 6-month course.

The teacher explained how important English is, and how much better the students' lives would be once they had learned English.

'To confirm the effectiveness of this approach, I invite you to observe students who have finished the course and are now at an advanced level,' the teacher said.

'For example, if you were to go to the US and pronounce the word "ship" like "sheep", they would sell you a sheep to ride instead of a ship to travel in.'

'Do you want people to like you, and do you want to enjoy speaking English? Yes or no?' said the teacher.

'Yes, of course!' said the students.

'Then repeat the words as loudly and accurately as possible,' said the teacher. 'It's like singing: if you have a good voice, you are more likely to enjoy singing to yourself.'

The teacher played words in the authentic target language from a CD recording, and asked the students to repeat the words after him, complimenting them on their performance.

The teacher taught the students the word order of imperative sentences in their mother tongue, as follows: "infinitive without "to" + object + adverb of manner + adverb of place + adverb of time'.

When the students experienced problems, the teacher drew their attention to the word-order examples and asked them to correct their own work.

'For example,' said the teacher, 'the word "parrot" means "your feathers" in your mother tongue, and because a parrot has beautiful feathers you can relate these words to each other.'

\section{Principle(s)}

A language teacher should establish a friendly relationship with his/her students from the very beginning.

Language students feel more motivated to learn if they know what they will be taught during the course.

Students learn better if they understand the real importance of learning a language.

If students are certain of the usefulness of their teachers' approaches, they feel more inspired to learn.

Funny examples are more likely to stick in students' minds, thereby helping them to learn.

If students enjoy speaking correctly, they will push themselves to improve much more quickly.

Working with authentic examples of the language and complimenting students on their learning can be truly inspirational.

Just as in the mother tongue, imperative sentences should be learned first in English. Comparing the target language and the native language is a highly effective means of solving students' problems.

The teacher's help should be the last option for autonomous learners; students retain information better when they correct their own mistakes.

Encouraging students to connect target words with mother-language words can significantly improve students' learning, partly because this is a fun activity and partly due to the time taken to deliberate on the relationships between words, even if a similarity is not found. 
The teacher played an authentic English film to show the students how romantic and beautiful their accents could be if they stressed particular syllables according to the rules for English phonetics.

After making the importance of listening clear to the students, the teacher wrote down some key features of spoken English that they would be expected to recognise when listening to English.

A copy of the CD without section headings had already been given to each student to enable them to practise the vocabulary before attending the class.

Most of the headings of sections of the CD were inspirational, such as 'the importance of ambition', 'the importance of self-confidence', 'no pain, no gain' and 'the daily use of English in our lives'.

'In the next class I will ask you to say the sentences we have already studied at random. Not only will you have to say the exact sentences; you should also try to pronounce them as accurately as possible.'

Each 2-hour class was divided into three parts: listening, speaking and story-telling.

'I know this is your first experience, and it's really hard for you. I just want you to do your best and have fun, and if you can't say something, ask in English for the correct word.'

The students took turns speaking, and all were enthusiastically complimented and inspired by their teacher, regardless of the quality of their speaking.

The teacher began with a story called ' $\mathrm{Mr}$ Brown'.

If the students made grammatical mistakes when translating sentences into the target language, the teacher drew their attention to the designated pages on grammar in their 'speaking' booklet.

When the students' intonation and pronunciation differed from those on the $\mathrm{CD}$, the teacher played the recording back and encouraged them to speak in a more native-like way, to enjoy themselves more.

When a student was only able to identify the words 'what' and 'doing' in the question 'what are you doing?', the teacher encouraged him to use his grammatical knowledge to guess the rest of the sentence.

The teacher advised the students to focus on the whole context and not on single sentences or words when listening.
Demonstrating the real beauty of standard pronunciation by showing a film in the authentic language can inspire students to standardise their spoken English.

Providing listening points can significantly improve students' listening skills if students are already highly motivated to learn.

Listening skills can be improved much more rapidly if students practise effectively at home.

Language learners should always be encouraged and motivated to learn either directly or indirectly.

Listening activities should be designed to help students with their speaking.

Students learn language skills more effectively and become less bored if diverse techniques are used.

The teacher should minimise his/her students' stress by making them understand that making mistakes is normal and part of their learning.

At first, the teacher should focus on his/her students' progress, not on ensuring that they speak the language perfectly; learning will happen in time if students are sufficiently inspired.

Using stories to teach grammar and formulate sentences can make the language more meaningful and more fun, which in turn speeds up language acquisition.

Students should be empowered to take control of their own learning as much as possible, increasing their self-confidence in learning.

Accurate pronunciation should be made to seem as enjoyable as possible to motivate students to learn to pronounce words with enthusiasm.

Teachers should only help their students when necessary. They should teach their students how to use their own grammatical knowledge to improve their listening.

Focusing on the whole context of a sentence or passage can significantly help students with their listening. 
The teacher told the students that almost all of his intermediate and advanced English learners were part of a virtual (WhatsApp) group, enabling them not only to exchange information but to send English music, English poems and helpful proverbs in English to increase their understanding of the language.

The teacher provided examples of certain former students who had experienced similar problems, such as those who misheard the words 'upset' and 'upstage' as 'set' and 'stage'.

The teacher told the students that from a certain point onward they would be required to express their feelings about their learning experience in English..

The teacher reassured his students that if there are eight people in a class, they are eight friends, and no-one should be ashamed of expressing their thoughts in front of their friends

'You should behave like babies,' said the teacher. 'Don't be afraid of making mistakes when learning to speak the language until you are familiar with spoken English.'

'I can't help my stress, teacher,' one student commented.

'You know, my dear,' said the teacher, 'we have two kinds of stress: first, positive stress, which I call "strong will". This increases blood flow to our muscles and carries glucose to our brain, making us better learners. The other is negative stress, which I call the "bogeyman". Negative stress is caused by something that doesn't exist, which we have made up in our minds, and which impedes our learning.' impedes us from learning."

"If you are scared of the bogeyman, try being in the dark; if you are scared of heights, stand in a high place; and if you are scared of speaking the target language, simply try speaking it. I can assure you that these kinds of illogical stress will disappear after a while.'

Next, the teacher quietly played a piece of light, beautiful music to the class, and told them to have fun talking about the importance of love to people's lives.

The teacher implemented a different approach to speaking in each of three weekly speaking sessions, and played a different piece of light music in each session.

The students were also asked to speak English when playing sports such as dodgeball, volleyball and football during field trips. They had to speak English throughout the games to describe their moves.
Learning is greatly enhanced when students are both learning and having fun in a large community of language learners in a virtual environment.

Providing examples of FL students who have encountered similar problems can help students to better understand the importance of the teacher's teaching points.

Students feel relieved when they are able to express themselves in the target language, and their descriptions of their feelings sometimes provide the teacher with valuable information on areas in need of further work.

Establishing friendly relationships between students can considerably reduce the stress experienced during learning.

Showing the students how natural it is to make mistakes by reminding them how effortlessly they have already learned one language can truly lift their spirits.

Language learners should be told how helpful their stress can be if they are able to take advantage of it. Comparing the students' stress to an imaginary creature of which they were afraid during childhood helped them to realise how illogical their stress could be.

Teaching language learners how to overcome their stress plays a crucial role in improving their language learning.

Setting a romantic topic for discussion, which is usually students' favourite type of topic, and playing romantic music can make students calmer and considerably improve their learning.

Playing different types of light music and introducing different speaking activities can help students to have fun and become enthusiastic about speaking an FL.

Playing sports during field trips can be immensely helpful to FL students for three main reasons. 1. These activities are fun. 2. They allow students to use the target language in a real-life context. 3 . They can encourage the body to secrete endorphins, which make students feel happier and thus learn more quickly. 
In some sessions, the teacher invited the students to visit a Universal Language Village created by the teacher as an environment similar to a secondlanguage context.
The teacher acted not as a teacher but as a family member; merely another resident at the Universal Language Village.

After 3 months, once the students' vocabulary had reached an appropriate level, the teacher used an English song with more words and idiomatic expressions as a listening activity.

The teacher taught the students to sing along with one of the most successful songs released by Adele, a well-known popular singer, named 'Hello'. This was one of the students' favourite songs.

While the students were singing, the teacher paused the song and said, 'Now I want to pronounce the words of the song words with and without the right stress patterns'. After saying the word 'hello' twice, once with and once without stress on the letter ' 1 ', he showed the students how much more romantic their singing could be if they obeyed the phonetic rules of English.
Creating a place similar to a second-language

context can be very helpful for;

FL learners, who rarely have access to targetlanguage environments. Meaningful interactions in situations resembling those of real life not only equip students with essential communicative skills but provide an opportunity for authentic learning that is not available in a conventional classroom environment.

To create a more realistic second language like context, the teacher should act as another member of the group rather than an instructor to speed up the students' acquisition of the language.

A language teacher should not rush the teaching of language skills, and should move step by step from easier to more difficult activities to ensure that the students remain confident in their learning.

Teaching students to sing along with one of their favourite songs is always one of the most fun and effective ways of teaching a language.

Students are more cooperative and more careful to obey pronunciation rules if they enjoy singing.

\section{Conclusion}

One of the fundamental goals of the proposed approach is to teach students how to use an FL in real-life contexts. To do this as rapidly as possible, the teacher must work on the basic grammar and vocabulary of the target language by providing many examples with contextual applications to encourage the students to make direct connections between the target language and its meaning. The teacher can continuously improve his/her students' motivation and elicit their passion and excitement by inspiring them to use the language while listening to music and playing sports. The use of diverse FL techniques, especially when teaching learners to speak an FL, is believed to play a key role in their learning. In sum, teachers using this approach take the role of compassionate counsellors who care for their students, attempt to understand their feelings, show them how to have fun and relieve their stress. The students are initially beginners who need to follow their teacher's instructions precisely. After reaching a sufficiently advanced level, they become more autonomous learners.

The approach does not involve a formal process of evaluation or a test; however, the teacher constantly evaluates his/her students and asks them to use their knowledge in new contexts. At first, the interaction is one-sided: directed from the teacher to the students. After the students reach a certain level, both student to student and teacher to student interaction occurs. Speaking, listening and writing are emphasised from the very beginning. Reading receives little attention. Pronunciation, grammar and vocabulary are emphasised, and questions in these areas are asked in every session. These skills are often learned through story-writing, story-telling, speaking and listening. The teacher speaks the target language from the very beginning. The students, whose vocabulary in English is limited, first speak their mother tongue, but after reaching a certain level are required to speak solely in the target language. The teacher uses both the target language and the native language to comfort and motivate the students and to teach them basic grammatical points.

The intention of this paper is not to demonstrate the superiority of the proposed approach to others; however, it does provide some new FL teaching procedures that may help to decrease the time taken to attain the required language proficiency. Moreover, anything that can make a change in the students' learning is an effective teaching ( Birjandi \& Rezanejad, 2014).The proposed approach was found to help the FL learners involved in the study to become competent users of EFL by the end of a 6-month course. Different teaching methods may be suitable for different environments or students (Larsen-Freeman, 1986). Further research is required to assess the efficacy of this teaching approach in other FL teaching contexts, because one study is insufficient to demonstrate the validity of the approach. As a result, the 
study lacks a theoretical background. However, it does provide other researchers with a good basis for comparison. Another potential limitation of the study is the validity of the questionnaire survey, which should be tested in future research.

\section{References}

Birjandi, P., \& Rezanejad, A. (2014). How can I teach effectively when . . . : An exploration of factors affecting willingness to teach effectively (WTTE) among EFL teachers. International Journal of Applied Linguistics \& English Literature, 3(4), 168-176.

Howatt, A. P. R. \& Smith, R. (2014). The history of teaching English as a Foreign language, from a British and European perspective. Language and History 57(1), 75-95.

Larsen-Freeman, D. (1986). Techniques and Principles in Language Teaching. Cambridge: Cambridge University Press.

Richards, C. J. \& Rodgers S. T. (2014). Approaches and Methods in Language Teaching (3rd Ed.). Cambridge, United Kingdom: Cambridge University Press.

Spada, N. (1987). Relationships between instructional differences and learning outcomes: A process-product study of communicative language teaching. Applied Linguistics 8, 137-155. 